\title{
Changes in the Secretory Acinar Cells of the Rat Parotid Gland During Aging
}

\author{
SUN-KEE KIM \\ Research Service, V.A. Medical Center, and the Department of Anatomy and \\ Cell Biology, The University of Michigan Medical School, Ann Arbor, \\ MI 48105
}

\begin{abstract}
The secretory acinar cells of parotid glands from rats of varying ages have been examined by electron microscopy to determine what agerelated changes occur in these cells. The most prominent change noted in these cells is the progressive increase in the amount of lipofuscin granules with age. Lipofuscin granules are membrane-bound structures consisting of lipids, other subcomponents, and a matrix. In addition, these cells contain lipid droplets that are not associated with any other components and tend to accumulate at the base of the cells in older rats. Also, many acinar cells in the glands of old rats contain altered secretory granules which appear to be in the process of degeneration. The accumulation of lipid and degenerating secretory granules appears to be related to the reduced level of cellular secretory activity in the glands of older rats. It is possible that these two types of inclusions contribute to the formation of lipofuscin granules. Lipofuscin and degenerating secretory granules are associated with acid phosphatase, which is demonstrated cytochemically, indicating that these granules are lysosomal structures.
\end{abstract}

Salivary glands, like many other organs, undergo changes in structure and function with age. It has been reported that reductions occur in the amylase content in saliva (Meyer et al., 1937; Meyer and Necheles, 1940; Chilla et al., 1974), as well as the secretion and the rate of flow of saliva (Bertram, 1967). We have shown previously that the rate of protein synthesis declines with age in rat parotid glands (Kim et al.; 1980, Kim, 1981), and that this decline reflects the reduction in the synthesis of secretory proteins (Kim et al., 1982; Kim and Calkins, 1983). These age-related changes that affect the salivary content and the synthesis of protein suggest that alterations occur in the structural elements of the secretory acinar cells of the gland.

Age-related changes described in human salivary glands at the light microscope level include the accumulations of fibrous and fatty tissues, a gradual replacement of the parenchyma by these stromal tissues (Hamperl, 1931; Andrew, 1952; Waterhouse et al., 1973), the increase in ductal volume (Hamperl, 1931; Scott, 1977a,b), lymphocytic infiltration (Hamperl, 1931), and the occurrence of oncocytes (Hamperl, 1931, 1933). Similar changes have been also noted in salivary glands of animals. Andrew (1949) has described fatty degeneration of parenchymal tissues, the occurrence of oncocytes and lymphocytic infiltration in parotid glands of the rat. However, it remains uncertain what changes occur in secretory acinar cells of the salivary gland.

In this study, acinar cells of the rat parotid gland were examined by electron microscopy and ultrastructural cytochemistry to determine what changes occur in the cellular organelles during aging. One of the most notable changes which occurs in these cells in relation to aging is the increase in the number of lipofuscin granules, as appears to be the case in rat submandibular glands (Bogart, 1970). Also, there are lipid droplets that tend to form aggregates at the base of the cells in old rats. Occasionally, these lipid droplets and lipofuscin granules form large masses that fill much of the cytoplasm. In addition, many acinar cells, especially those of old rats, contain degenerating secretory

Received September 28, 1983; accepted January 24, 1984 
granules that may result from the reduced level of cellular secretory activity.

\section{MATERIALS AND METHODS Animals}

Male, Sprague-Dawley rats of 2, 12, 18, 24, 30 , and 36 months of age were used for this study. These rats were obtained from an aging colony maintained at Charles River Breeding Laboratories in Portage, Michigan. The rats were kept from food the night before they were sacrificed.

\section{Methods}

The rats were perfused through the heart with a mixture of $1 \%$ paraformaldehyde and $1.5 \%$ glutaralheyde buffered with $0.1 \mathrm{M}$ sodium cacodylate to $\mathrm{pH}$ 7.4. The parotid glands were removed, sliced into smaller pieces, and further fixed in the same fixative for another hour. The tissues were postfixed in $\mathrm{O}_{\mathrm{s}} \mathrm{O}_{4}$, and prepared for electron microscopy as previously described (Kim et al., 1980; Kim, 1981).

For a cytochemical demonstration of acid phosphatase, aldehyde-fixed tissues were further sliced with a scalpel blade and rinsed overnight in buffer. Tissue slices were incubated in a medium containing cytidine monophosphate (Sigma) as substrate for 45 minutes (Novikoff et al., 1971). Control incubation was done in the absence of substrate. After incubation, tissues were processed as above for electron microscopy. Thin sections of incubated tissues were viewed in the electron microscope after staining briefly with uranyl acetate.

To estimate the relative volumes of lipid and lipofuscin granules in the acinar cells and the proportion of acinar cells with degenerating secretory granules at various ages, point counting was done using electron micrographs of selected cells (Weibel and Bolender, 1973; Bolender, 1974). These cells were randomly selected and photographed in sections of 3 Epon-embedded blocks of parotid glands from three rats per age group. For point counting, only those cells which revealed a nucleus and bordered a secretory lumen were selected. A square lattice system of $1 \mathrm{~cm}^{2}$, drawn on a celluloid sheet, was placed over the micrographs and test points over lipid-lipofuscin, or secretory granules, were counted. Volume densities were obtained by using the formula $\mathrm{V}_{\mathrm{vi}}=\mathrm{Pi} / \mathrm{Pt}$, where Pi represents the number of test points over particular granules of interest and $\mathrm{Pt}$ represents the total number of test points over the cell.

\section{OBSERVATIONS}

One difference that is pronounced at the light microscope level in the parotid glands of progressively older rats is the increasing amount of fat in the connective tissue stroma. As we have described previously (Kim et al., 1980; Kim, 1981), fat, which is first detected in the glands of 12-month-old rats, increases in amounts with age. However, the age-related differences that involve the secretory acini are less obvious at this level.

The overall appearances of the secretory acinar cells at the electron microscope level are not significantly different among the age groups. The nucleus and parallel arrays of endoplasmic reticulum occupy the basal portion in the acinar cells of all age groups, while secretory granules, as well as other cytoplasmic organelles, fill much of the remainder of the cytoplasmic space (Figs. 1-3). These cells are arranged around a secretory lumen (Figs. 1-3) and form an acinus. No unusual feature attributable to age differences has been noted in any of the organelles of these cells with the exception of those described below.

Many parotid acinar cells of 12-month-old and older rats possess lipid-containing structures, which were previously described as lipofuscin or lipofuscin pigment granules. At 12 months, a few of these granules are present in some acinar cells (Fig. 1). However, the number of cells containing lipofuscin granules, as well as the number of these granules in each cell, increases in the older age groups (Table 1; Figs. 2, 3). In the acinar cells of 36-month-old rats, lipofuscin granules occupy about $2 \%$ of the cell volume (Ta-

Fig. 1. A portion of the parotid gland from a 12-monthold rat showing the appearance of acinar cells. In each acinar cell, the nucleus and parallel arrays of rough endoplasmic reticulum occupy the basal portion, while secretory granules and other organelles fill much of the remainder of the cytoplasm. Lipofuscin granules $(\mathrm{Lf})$ are present only in some cells at this age. The lumen (Lu) of the acinus is indicated. $\times 7,000$.

Fig. 2. A portion of the parotid gland from a 30-monthold rat showing the appearance of acinar cells. The arrangement of various organelles in these cells is similar to that in the acinar cells of younger rats. However, most of the acinar cells at this age contain lipofuscin granules $(\mathrm{Lf})$, and the number of these granules in each cell is increased. In some cells, these pigment granules form a large mass as in a cell at the upper right corner. In addition, there are numerous, single lipid granules (Lp) that are not associated with any other subcomponents. $\mathrm{Lu}$ indicates the secretory lumina. $\times 6,000$. 

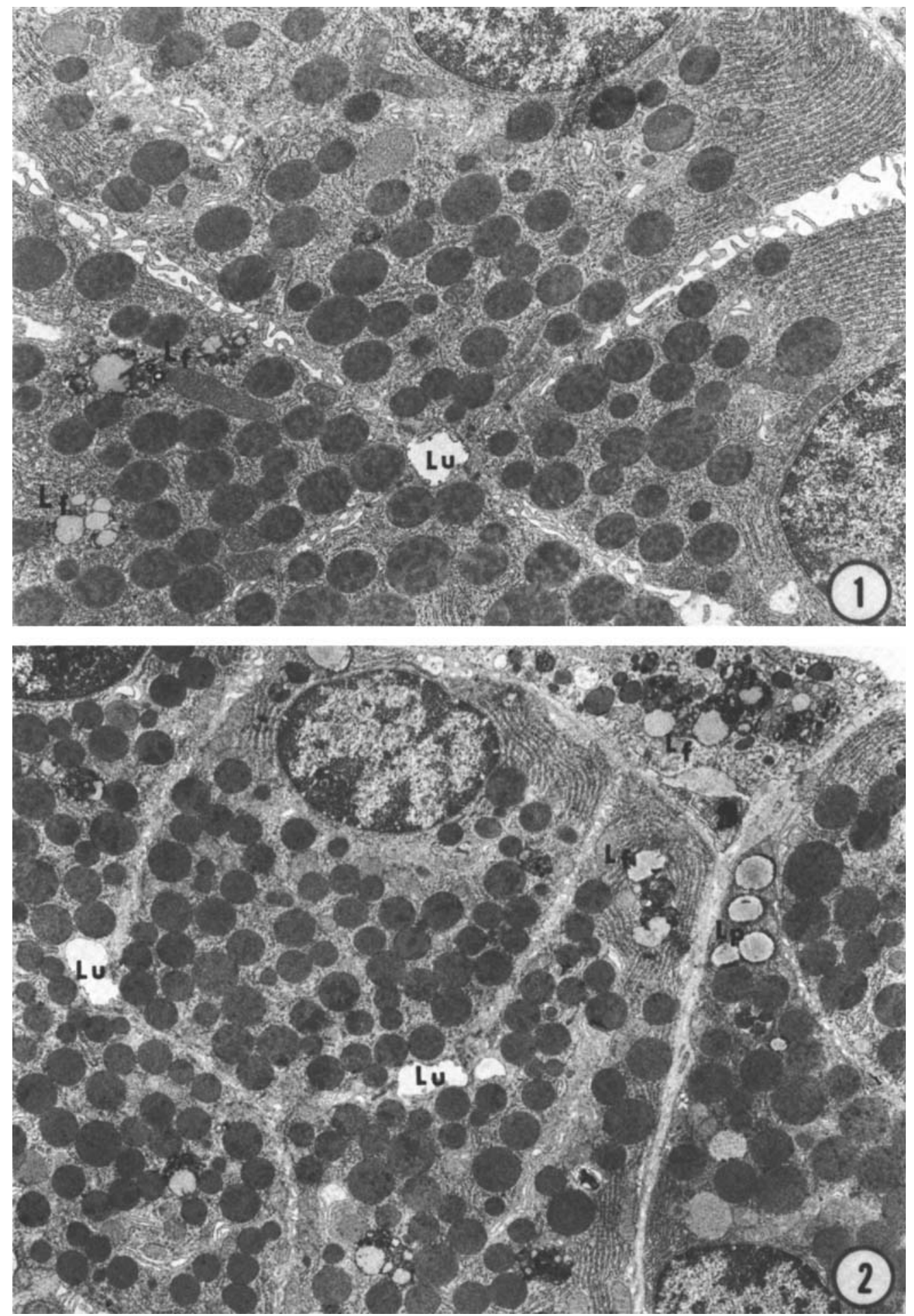


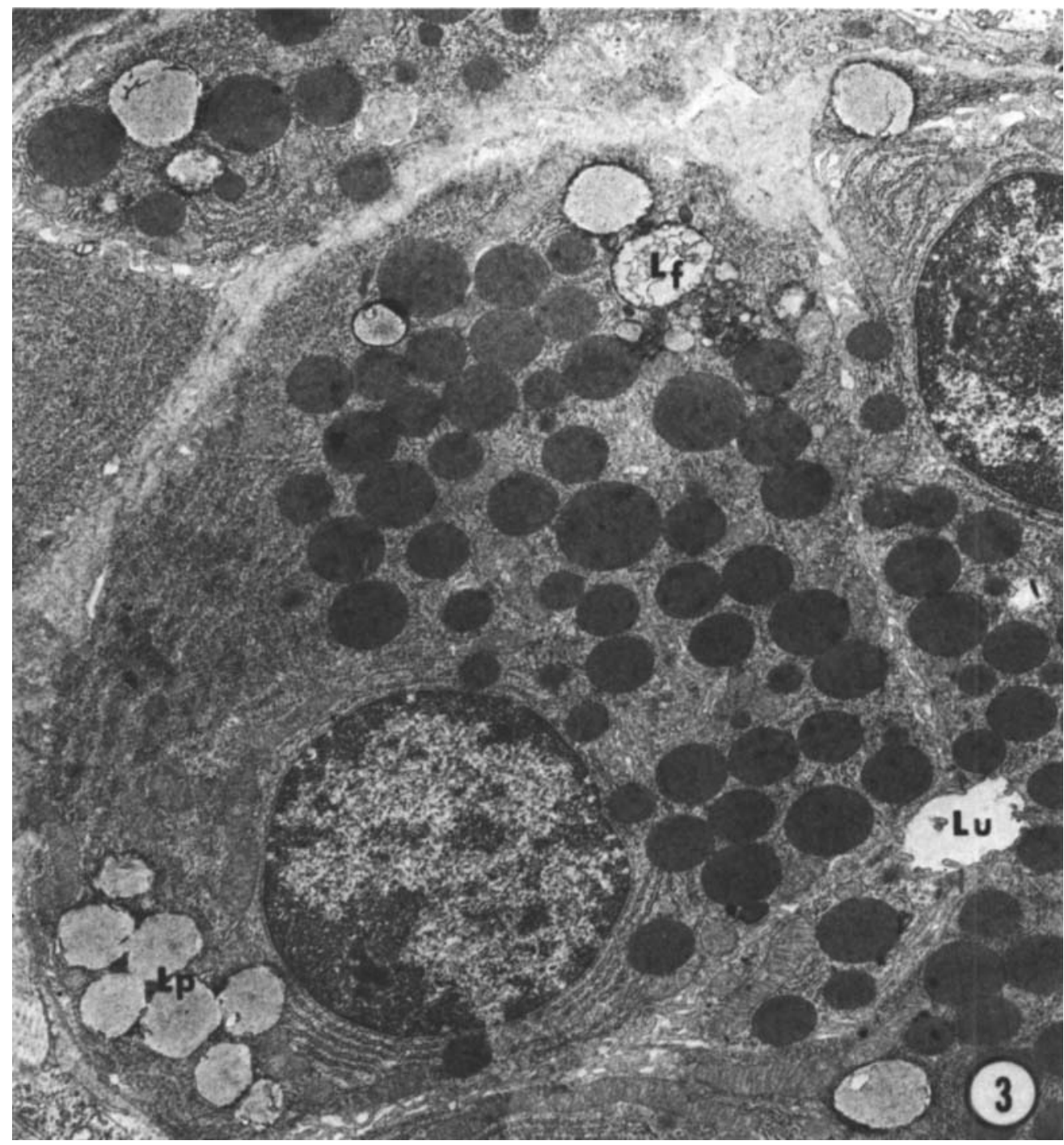

Fig. 3. A portion of parotid gland from a 30-monthold rat, showing the typical appearance of acinar cells in an old rat. As the cell in the center of the micrograph shows, the acinar cells at this age typically contain lipofuscin granules (Lf) and lipid granules (Lp) which tend

ble 1). In some acinar cells of these old rats, lipofuscin granules are not only numerous, but they tend to aggregate and form large masses (Figs. 2, 7).

Lipofuscin granules are membrane-bound structures consisting of subcomponents of lipids, electron dense granular materials and a matrix (Fig. 4). Lipofuscin granules are generally scattered in the cytoplasm but have not been observed in the nucleus. Occasion- to cluster at the base of the cell near the nucleus. Secretory granules and other organelles present in this cell do not reveal any unusual appearances. The lumen (Lu) of the acinus is also shown. $\times 9,500$.

ally, these granules are located in close proximity to the Golgi complex, especially within the trans aspect of the organelle (Fig. 5). Acid phosphatase is detected in association with these granules as evidenced by the presence of reaction products in the granulated structures and in the matrix (Fig. 6a). The reaction products for acid phosphatase activity are also present in other lysosomal structures and in the Golgi complex. In the latter 
TABLE 1. Distribution of lipid and lipofusein granules in rat parotid acinar cells

\begin{tabular}{lccc}
\hline & & $\begin{array}{c}\text { Percent of total cell volume } \\
\text { (mean } \pm \mathrm{SE} \text { ) }\end{array}$ \\
\cline { 3 - 4 } $\begin{array}{l}\text { Age } \\
\text { (months) }\end{array}$ & $\begin{array}{c}\text { Number } \\
\text { of cells }\end{array}$ & $\begin{array}{c}\text { Lipid } \\
\text { granules }\end{array}$ & $\begin{array}{c}\text { Lipofuscin } \\
\text { granules }\end{array}$ \\
\hline 2 & 36 & $\mathbf{1 . 0 6 \pm 0 . 6 2}$ & $0.033 \pm 0.033$ \\
12 & 57 & $0.49 \pm 0.13$ & $0.628 \pm 0.153$ \\
18 & 37 & $0.49 \pm 0.12$ & $0.853 \pm 0.200$ \\
24 & 45 & $1.09 \pm 0.30$ & $0.875 \pm 0.194$ \\
30 & 52 & $1.57 \pm 0.44$ & $0.934 \pm 0.332$ \\
36 & 45 & $0.82 \pm 0.48$ & $2.074 \pm 0.476$ \\
\hline
\end{tabular}

organelle, deposits of reaction products occur in the inner cisternal and condensing vacuoles (Fig. 6b).

In addition to the lipofuscin granules, the acinar cells also contain lipid droplets that are not associated with any other components. These lipid droplets tend to aggregate at the base of the nucleus in older rats, although they also occur singly (Fig. 3). Thus, many acinar cells in old rats contain both lipofuscin granules and lipid droplets (Fig. 3 ). However, similar lipid droplets are also found in substantial numbers in the acinar cells of the glands in 2-month-old rats (Table 1). In these young rats, lipid droplets are scattered in the cytoplasm and do not form clusters near the nucleus. Some acinar cells of 30- and 36-month-old rats reveal a large lipid droplet which occupies much of the cytoplasm. (Fig. 8). However, these cells with large lipid droplets or a mass of lipofuscin granules (Fig. 7) in their cytoplasm are not detected in all rats of these ages.

The third change that seems to be related to age differences involves the secretory granules. Many acinar cells of 12-month-old and older rats (Table 2) possess membranebound structures that are the same size or somewhat larger than the homogeneously dense secretory granules (Fig. 9). These membrane-bound structures consist of clumps of dense material scattered in a matrix that is less dense than that of the secretory granules. The acinar cells with these membrane-bound bodies, which appear to be altered secretory granules, are not frequently encountered in the glands of 2 . month-old rats. However, these cells with altered granules increase in number in 12 month-old and older rats, and are especially numerous in 36-month-old rats. (Table 2, Fig. 9). These altered granules also reveal acid phosphatase activity and appear to be the secretory granules in the process of degeneration; deposits of reaction products occur in the matrix of these granules (Fig. 9, inset).

\section{DISCUSSION}

The amount of fat seems to increase with age in parotid glands of the rats observed in this study, as has been reported previously in other salivary glands (Hamperl, 1931; Andrew, 1952; Waterhouse et al., 1973). Some other age-related changes, such as the occurrence of oncocytes (Hamperl, 1931, 1933) or the elevated level of lymphocytic infiltration (Hamperl, 1931), have not been detected in this study. Also, it is not very obvious whether or not the relative volumes of the ducts change with age as reported previously (Hamperl, 1931; Scott, 1977a, b).

The most noticeable change that occurs in the acinar cells of the rat parotid gland during aging is the accumulation of lipofuscin pigment granules. Although lipofuscin pigments have been found in some cells of young tissues (Essner and Novikoff, 1960; Frank and Christensen, 1968; Goldfischer and Bernstein, 1969), the presence of these pigment granules is one of the most consistent features observed in widely different types of tissues from aged animals (Strehler et al., 1959; Reichel, 1968). In parotid glands, lipofuscin granules are found only rarely in the acinar cells of 2-month-old rats, but increase in number with age. Similar granules are present also in submandibular glands of old rats (Bogart, 1970).

Lipofuscin granules of the rat parotid gland are similar in structure to those that occur in cells of other tissues and are associated with acid phosphatase, as in the liver (Essner and Novikoff, 1961), mammary gland (Miyawaki, 1965), neurons (Brunk and Ericsson, 1972), and interstitial cells of the testis (Frank and Christensen, 1968). Since acid 

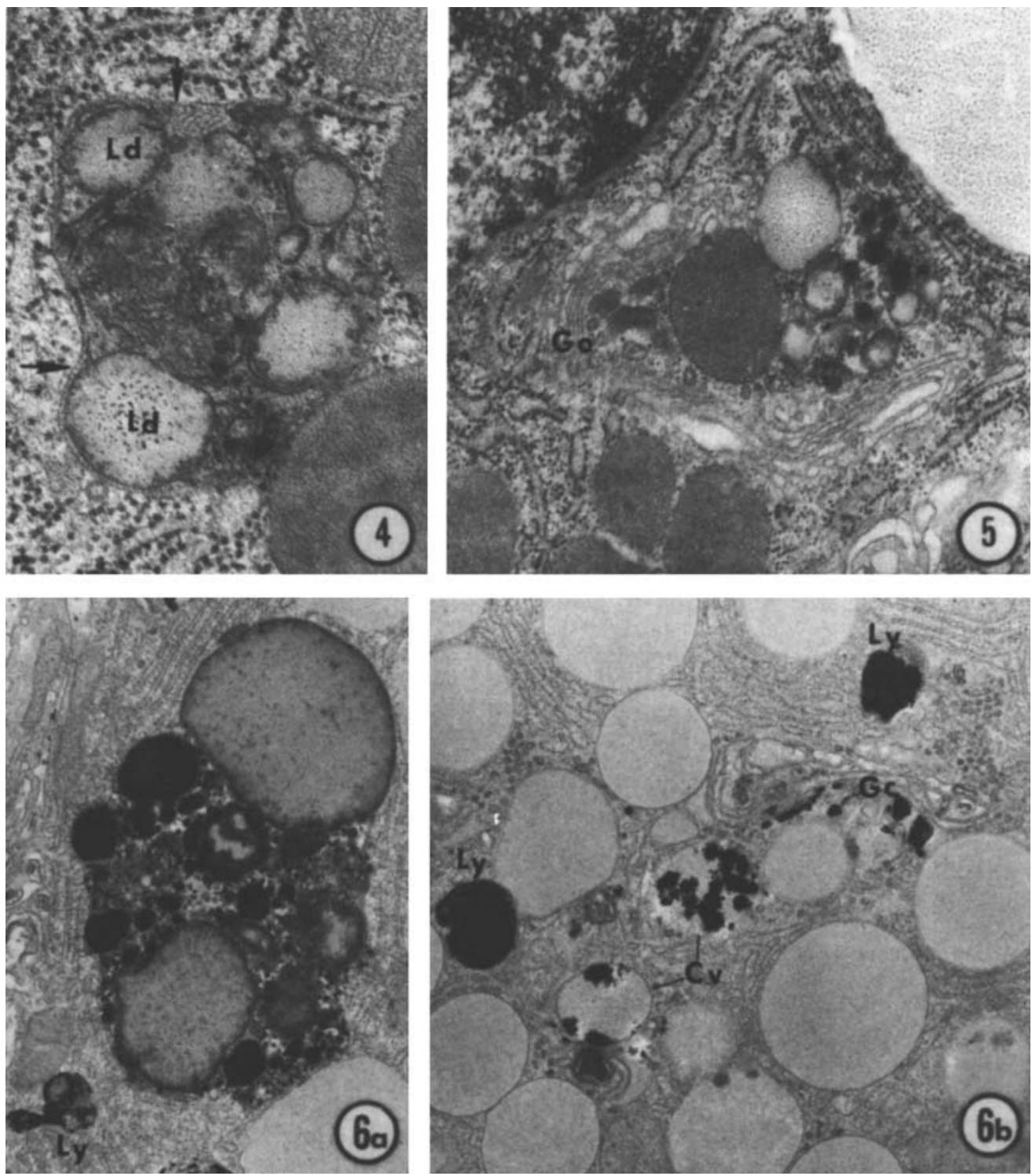

Figs. 4, 5. Portions of acinar cells from parotid glands of 30-month-old rats showing lipofuscin granules at a high magnification.

Fig. 4. Lipid droplets (Ld) of various sizes and granulated structures of varying density make up the bulk of the lipofuscin granule, which is bound by a membrane (arrows). $\times 55,000$.

Fig. 5. Lipofuscin granules are found occasionally in close contact with the Golgi complex (Go), especially in the trans aspect of the organelle. $\times 27,000$.
Fig. 6. Portions of acinar cells from parotid glands of 24-month-old rats incubated to localize the sites of acid phosphatase activity. a) Deposits of reaction products occur in the granulated subcomponents and the matrix of the lipofuscin granule, as well as in adjacent lysosomes (Ly). b) The reaction products of the enzyme activity are also localized in the innermost cistern (Gc) and condensing vacuoles (Cv) of the Golgi complex. In addition, lysosomes (Ly) in this micrograph also show the enzyme activity. $\times 18,000$. 
phosphatase activity is also detected in other lysosomal structures of the rat parotid acinar cells, lipofuscin granules are probably a type of lysosomal structure, or represent the residue of the lysosomal digestion products (Brunk and Ericsson, 1972).

According to Pearse (1960), lipofuscin granules result from the oxidation of lipids, and the pigmentation rises with the progress of oxidation. However, the origin of lipid and other subcomponents of the lipofuscin gran. ules remains uncertain. The transformation of mitochondria (Duncan et al., 1960; Hess 1955) and Golgi complexes (Bondareff, 1957; Gatenby and Moussa, 1950; Gatenby, 1953) to lipofuscin granules has been suggested, but there is no strong evidence in support of these suggestions. The close spatial relationship shown by the lipofuscin granules and the Golgi complexes in rat parotid glands, together with the presence of acid phosphatase activity in both of these structures, can suggest that the Golgi complex plays a role in the formation of lipofuscin granules. Deposits of reaction products for acid phosphatase occur in the inner cisternae and condensing vacuoles of the Golgi complex, as has been described previously (Hand, 1972). These elements with acid phosphatase activity are comparable to those described as GERL (Novikoff et al., 1971). It is unknown whether these Golgi elements are directly involved in the formation of lipofuscin granules.

Parotid acinar cells of the rat possess lipid droplets and degenerating secretory granules. It is possible that these two inclusions contribute to the formaton of lipofuscin granules. The origin of these lipid droplets is also uncertain. The fact that these lipid droplets are as numerous in young glands as in older glands may indicate that the presence of this lipid is related to the cellular metabolic activity rather than to aging. Similar lipid droplets are found in the acinar cells of the parotid gland in rats following the stimulated secretion of stored secretory granules (Simpson, 1972; Lillie and Han, 1973; our unpublished observation) and after a period of starvation (Hand, 1972).

The accumulation of lipid droplets in parotid acinar cells in old rats may be related to the reduced level of cellular secretory activity, as has been suggested to be the case during atrophy of the gland caused by a liquid diet (Wilborn and Schneyer, 1970; Hand, 1972). The presence of a large number of acinar cells which possess altered degenerating secretory granules supports the suggestion that the cellular secretory activity is reduced in glands of old rats. Degenerating secretory granules of similar appearance have been observed in parotid acinar cells following the starvation of rats for about a day (Hand, 1972) and following a chronic treatment with reserpine (Sepster et al., 1979). In these starved rats, the altered secretory granules are associated with acid phosphatase, indicating that lysosomes are involved in the destruction of "old" secretory granules (Hand, 1972). It is also possible that these droplets are rapidly broken down and reutilized in young rats, or excreted out of the cells, whereas in older rats these processes are much slower, resulting in the accumulation of lipids in the form of single granules or lipofuscin granules. In fact, it has been suggested that the accumulation of lipofuscin bodies is due to the inability of cells to rid of the residues of lysosomal digestion products by exocytosis (Brunk and Ericsson, 1972).

The amount of lipofuscin granules increases progressively with age in rat parotid glands. However, even in the glands of 36 month-old rats, these granules occupy only $2 \%$ of the total cell volume, with the exception of a few cells which become filled with the pigment granules. Similar volume fractions of lipofuscin granules have been reported in neurons of the supraoptic ganglion of the aging mouse (Davies and Fotheringham, 1981). Therefore, it is unlikely that the increasing number of lipofuscin granules affects the cell function by replacing other cytoplasmic organelles. For example, the rate of protein synthesis in rat parotid glands declines by about $50 \%$ between the ages of 2 and 30 months (Kim et al., 1980). Thus, it seems unlikely that the mere presence of lipofuscin granules affects protein synthesis to this degree.

\begin{tabular}{lccc}
\multicolumn{5}{c}{$\begin{array}{c}\text { TABLE 2. Proportions of rat parotid acinar cell with } \\
\text { degenerating secretory granules (DSG) }\end{array}$} \\
$\begin{array}{l}\text { Age } \\
\text { (months) }\end{array}$ & $\begin{array}{c}\text { Total number of } \\
\text { cells examined }\end{array}$ & $\begin{array}{c}\text { Number of cells } \\
\text { with DSG }\end{array}$ & Percentage \\
\hline 2 & 56 & 6 & 11 \\
12 & 89 & 32 & 36 \\
18 & 97 & 28 & 29 \\
24 & 90 & 27 & 30 \\
30 & 67 & 18 & 27 \\
36 & 89 & 49 & 55 \\
\hline
\end{tabular}



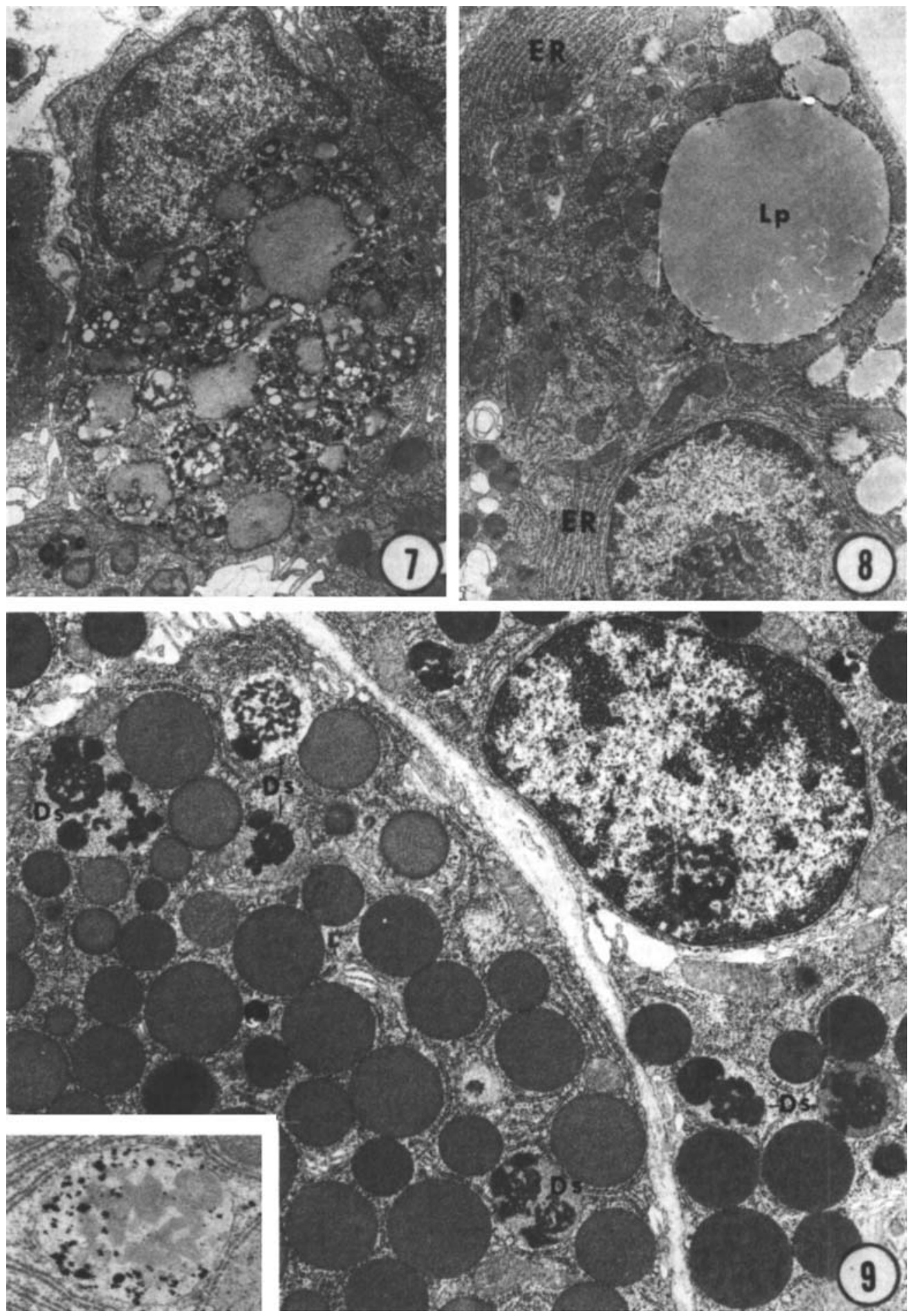
One likely explanation for the decline in protein synthesis in this gland during aging is the positive-feedback type of inhibition by secretory proteins that accumulate in the acinar cells of the older rats, presumably as a result of the reduced level of digestive activity related to aging. The increase in the number of acinar cells with degenerating secretory granules in the older rats supports the theory that secretory proteins are stored for prolonged periods of time in the older age groups. On the other hand, it is possible that age-related reductions in protein synthesis in other secretory functions involve quantitative alterations in the organelles that are concerned with these processes. In fact, it has been reported that the amount of rough-surfaced endoplasmic reticulum is reduced in submandibular acinar cells of aged rats (Bogart, 1970). We are in the process of analyzing the relative volumes of various cellular organelles in parotid acinar cells in rats of different ages.

\section{ACKNOWLEDGMEN'TS}

The technical assistance of Mrs. Virginia W. Hartog is gratefully acknowledged. The author also thanks Dr. Edward D. Allen for his help in preparing many of the electron micrographs used for morphometry in this study. This work was in part supported by the Veterans Administration and by grant AG00944 from the National Institutes of Health.

Figs. 7, 8. Acinar cells from parotid glands of 30month-old rats.

Fig. 7. Some acinar cells are filled with a large mass of lipofuscin granules which occupy the entire cytoplasmic space. $\times 8,000$.

Fig. 8. Some acinar cells possess a large lipid droplet (Lp) in the cytoplasm, which still retains much of the rough surfaced endoplasmic reticulum (ER). However, these two types of cells are found only occasionally in some glands of old rats. $\times 8,000$.

Fig. 9. A portion of parotid gland from a 36-monthold rat showing the altered secretory granules, which appear to be in the process of degeneration (Ds). These granules reveal clumps of dense material suspended in a light matrix and are present in many acinar cells. These degenerating granules are associated with acid phosphatase activity, as shown in the inset. Deposits of reaction product for this enzyme activity occur in the matrix of a degenerating granule. $\times 24,000$; inset, $\times 25,500$.

\section{LITERATURE CITED}

Andrew, W. (1949) Age changes in the parotid glands of Wistar Institute rats with special reference to the occurrence of oncocytes in senility. Am. J. Anat., 85:157197.

Andrew, W. (1952) A comparison of age changes in salivary glands of man and of the rat. J. Gerontol., 7:178190.

Bertram, U. (1967) Xerostomia: Clinical aspects, pathology and pathogenesis. Acta Odont. Scand., 25 (Suppl. 49): $1-126$

Bogart, B.I. (1970) The effect of aging on the rat submandibular gland: An ultrastructural, cytochemical and biochemical study. J. Morphol., 130:337-351.

Bolender, R.P. (1974) Stereological analysis of the guinea pig pancreas. I. Analytical model and quantitative description of nonstimulated pancreatic exocrine cells. J. Cell. Biol., 61:269-287.

Bondareff, W. (1957) Genesis of intracellular pigment in the spinal ganglia of senile rats. An electron microscope study, J. Gerontol, 12:364-369.

Brunk, U., and J.L.E. Ericsson (1972) Electron microscopic studies on rat brain neurons. Localization of acid phosphatase and mode of formation of lipofuscin bodies. J. Ultrastruct. Res., 38:1-15.

Chilla, R., H. Niemann, C. Arglebe, and G.F. Domagk (1974) Age-dependent changes in the alpha-isoamylase pattern of human and rat parotid glands. O.R.L. 36:372-382.

Davies, I., and P. Fotheringham (1981) Lipofuscin-does it affect cellular performance? Exp. Gerontol., 16:119125.

Duncan, D., D. Nall, and R. Morales (1960) Observations on the fine structure of old age pigment. J. Gerontol., 15:366-372.

Essner, E., and A.B. Novikoff (1960) Human hepatocellular pigments and lysosomes. J. Ultrastruct. Res., $3: 374$.

Essner, E., and A.B. Novikoff (1961) Localization of acid phosphatase activity-Hepatic lysosomes by means of electron microscopy. J. Biophys. Biochem. Cytol., 9:773.

Frank, A.L., and A.K. Christensen (1968) Localization of acid phosphatase in lipofuscin granules and possible autophagic vacuoles in interstitial cells of the guinea pig testis. J. Cell. Biol., 36:1-13.

Gatenby, J.B. (1953) The Golgi apparatus of the living sympathetic ganglion cell of the mouse, photographed by phase-contrast microscopy. J. Roy. Microse. Soc. 73:61-68.

Gatenby, J.B., and T.A.A. Moussa (1950) The sympathetic ganglion cell with sudan black and the zernike microscope. J. Roy. Microsc. Soc., 70:342-364.

Goldfischer, S., and J. Bernstein (1969) Lipofuscin (aging) pigment granules of the newborn human liver. $J$ Cell. Biol., 42:253-261.

Goodpasture, E,W. (1918) An anatomical study of senescence in dogs, with especial reference to the relation of cellular changes of age in tumors. J. Med. Res., 38:127190.

Hamperl, H. (1931) Beiträge zur normalen und pathologischen Histologic menschlicher Speicheldrüsen. Z. Zellforsch., 27:1-55.

Hamperl, H. (1933) Uber besondere Zellen in alternden Mundspeicheldrusen (Onkocyten) and ihre Bezieghungen zu den Adenolymphonen and Adenomen. Bererkungen zu der Arbeit von G. Steinhardt. Virchows Arch. f. Path. Anat., 291:704-605.

Hand, A.R. (1972) The effects of acute starvation on parotid acinar cells. Ultrastructural and cytochemical 
observations on ad libitum fed and starved rats. Am. J. Anat., 135:71-92.

Hess, A. (1955) The fine structure of young and old spinal ganglia. Anat. Rec., 123:399-424.

Kim, S.K. (1981) Age-related changes in the cellular level of amylase and protein synthesis in the rat parotid gland. J. Dent. Res., 60:738-747.

Kim, S.K., and D.W. Calkins (1983) Secretory protein synthesis in parotid glands of young and old rats. Arch. Oral Biol., 28:1-4.

Kim, S.K., D.W. Calkins, P.A. Weinhold, and S.S. Han (1982) Changes in the synthesis of exportable and nonexportable proteins in parotid glands during aging. Mech. Ageing Dev., 18:239-250.

Kim, S.K., P.A. Weinhold, S.S. Han, and D.J. Wagner (1980) Age-related decline in protein synthesis in the rat parotid gland. Exp. Gerontol., 15:77-85.

Lillie, J.H., and S.S. Han (1973) Secretory protein synthesis in the stimulated rat parotid gland. Temporal dissociation of the maximal response from secretion. J. Cell Biol., 59:708-721.

Miyawaki, H. (1965) Histochemistry and electron microscopy of iron containing granules, lysosomes, and lipofuscin in mouse mammary glands. J.N.C.I., 34:601609 .

Meyers, J., J.S. Golden, N. Steiner, and H. Necheles (1937) The ptyalin content of human saliva in old age. Am J. Physiol., 119:600-602.

Meyer, J., and H. Necheles (1940) Studies in old age. IV. The clinical significance of salivary, gastric and pancreatic secretion in the aged. J. Am. Med. Assoc., 115:2050-2053.

Novikoff, P.M., A.B. Novikoff, N. Quintana, and J.J. Hauw (1971) Golgi apparatus, GERL, and lysosomes of neurons in rat dorsal root ganglia, studied by thick section and thin section cytochemistry. J. Cell Biol., $50: 859-886$
Pearse, A.G.E. (1960) Histochemistry, Theoretical and Applied. Little Brown \& Co., Boston.

Reichel, W. (1968) Lipofuscin pigment accumulation and distribution in five rat organs as a function of age. $J$. Gerontol., 23:145-153.

Scott, J. (1977a) Quantitative age changes in the histological structure of human submandibular salivary glands. Arch. Oral Biol., 22:221-227.

Scott, J. (1977b) A morphometric study of age changes in the histology of the ducts of human submandibular salivary glands. Arch. Oral Biol., 22:243-249.

Sepster, M.E., S.S. Spicer, J.A.V. Simpson, and J.R. Martinez (1979) Altered granule discharge and amylase secretion of parotid glands in reserpine-treated rats. Lab. Invest., 41:256-264.

Simpson, J.A.V. (1972) Evidence of cell damage in rat salivary glands after isoproterenol. Anat. Rec. 173:437-452.

Strehler, B.L., D.D. Mark, A.S. Mildvan, and M.V. Gee (1959) Rate and magnitude of age pigment accumulation in the human myocardium. J. Gerontol., 14:430439.

Waterhouse, J.P., D.M. Chisholm, R.B. Winter, M. Patel, and R.S. Yale (1973) Replacement of functional parenchymal cells by fat and connective tissue in human submandibular salivary glands: An age-related change. J. Oral Pathol., 2:16-37.

Weibel, E.R, and R.P. Bolender (1973) Stereological techniques for electron microscopic morphometry. In: Principles and Techniques of Electron Microscopy, Vol. 3. M.A. Hayat, ed. van Nostrant Reinhold Co., New York, pp. 237-296.

Wilborn, W.H., and C.A. Schneyer (1970) Ultrastructural changes of rat parotid glands induced by a diet of liquid Metrecal. Zellforsch. Mikrosc. Anat., 103:111. 